\title{
GEREFORMEERDE PREDIKING: DIALEKTIES OF
}

\section{APODIKTIES ?}

Veral in die laaste twee dekades het daar op ons studeertafels en in ons teologiese klaskamers 'n groot aantal publikasies beland waarin die metode van die prediking 'n buitegewone belangstelling ontvang. Ons kan selfs praat van 'n klagstaat teen die gereformeerde prediking soos wat ons dit nog in ons Homiletiekklasse geleer het. En om in hierdie sewentiger-jare die verbete aanslag alleen met wapens uit die arsenaal van die twintiger jare se gereformeerde teologie af te weer, is ' $n$ onbegonne taak. Om maar slegs met $T$. Hoekstra se Gereformeerde Homiletiek in die arena van die hedendaagse diskussie in te stap, is 'n moeite wat so groot is soos Dawid s'n as hy met Saul se harnas die reus Goliat sou beveg. Dit word werklik tyd dat ons wakker skrik. Ons moet tot die besef kom dat die gereformeerde prediking in ons land in 'n krisis gekom het soos nog nooit vantevore nie.

Die grootste spanning in die prediking is nie slegs die vraag wat dat daar gepreek word nie, maar gewis ook hoe dat daar gepreek word. Nie alleen die eksklusiewe inhoud van die preek, $\mathrm{nl}$. Jesus Christus, en Hom as gekruisigde (2 Kor. $2: 2$ ), is vir die mens die grootste dwaasheid (1 Kor. 1 : 23) nie, maar ook die manier waarop God wil hê dat hierdie Evangelie moet oorgebring word, is vir hom verfoeilik - dwaas, belaglik. Juis die manier wat deur die Skrif self voorgeskryf word, is selfs vandag vir baie gereformeerdes so 'n dwaasheid dat hulle uit hulle pad gaan om dik boeke daaroor te skryf en onder die promotorskap van gereformeerde teoloë doktorsgrade daaroor verwerf. En steeds kry die stroom literatuur om teen die Skrif se „dwase metode" in die prediking te betoog, geen einde nie.

$O$, die dwaasheid van die prediking! En wat was die apostel Paulus in baie van hierdie mode-dissertasies die grootste dwaas, want as die Korinthiërs so 'n hartstogtelike verlange na „mooi preke" gehad het, dan kan hy maar slegs antwoord:

„My rede en my prediking was nie in oorredende woorde van menslike wysheid nie, maar in die betoning van gees en krag, sodat julle geloof nie in wysheid van mense sou bestaan nie, maar in die krag van God (1 Kor. $2: 4,5)$.

Ons wil so ver gaan om te beweer, dat as ons eers 'n slag baie goed gaan lees wat hier staan en die hele konteks van hierdie woorde gaan deurvors en dit met geloof aanvaar en gaan toepas ons, die predikers wat hier sit, van die eensaamste mense in die wêreld is; eensaam, omdat ons eenvoudig sal moet kies teen die sterk stroom sogenaamde ,gereformeerde" Homiletiek wat daar vanuit Suid-Afrika gepropageer word en selfs die toon aangee. Ons sal meer as ooit tevore onverbiddelik moet standpunt inneem teen die herlewing van die ou dialektiese redenaarskuns van die Griekse wysgere Zeno, Plato en Aristoteles, die Griekse retoriek en die wel- 
sprekendheid van die Sofiste waarmee Paulus te doen gekry het. Ons sal ons opnuut moet rekenskap gee oor die tematiese, skolastieke prediking van die Middeleeue, die Humanisme wat juis weer die Griekse retorika laat herleef en dan kan ons maar verder die lyn deurtrek... die Aufklärung, die Peïtisme, die Rasionalisme, die Subjektiwisme, die Etiese, ens. En verder, op hierdie selfde pad lê die dialektiek wat reeds in die vorige eeu deur Kierkegaard aangekondig is, deur Rudolf Otto verder ontwikkel is, deur Karl Barth deurgevoer is en ook die eksistensialisme wat in die Homiletiek vandag sy tienduisende verslaan.

$\mathrm{Ja}$, die dialektiek wat alreeds in die 5e eeu v.C. deur Zeno ontdek is en verder deur Aristoteles en ander wysgere ontwikkel is, ${ }^{\prime}$ het in ons tyd 'n nuwe momentum gekry. Die wêreld is beetgeneem deur die aangrypende eksistensialisme en in die $20 \mathrm{e}$ eeu het die teologie die kortste definisie ontwikkel van wat 'n preek is, $n l$. 'n dialoog. Vir 'n breedvoerige literatuurlys van die agtergronde hiervan verwys ons u na B. A. Müller se proefskrif: „Die Lewende Woord aan die mens van die hede" aan die Vrije Universiteit, Am!sterdam in $1961^{2}$ en wat weer op 'n onoorspronklike wyse oorgeneem is in G. J. Kotzé se proefskrif: „Hedendaagse Skrifprediking” aan die Stellenboschse Universiteit in $1963 .^{3}$

In beide hierdie twee gereformeerde teoloë in ons land (Kotzé neem Müller maar net oor) word die eis van die prediking as dialoog hartstogtelik gepropageer. Müller sê o.a.: „Die spanning van die prediking is die spanning van die Woord wat oop is vir 'n gesprek met die wêreld van ongeloof. Dié Woord laat die mens egter nie vry. blywend aan die gesprek deelneem nie, maar stel hom voor Gods bemoeienis met die wêreld en Sy appèl daaraan. Dit is die spanning tussen die konstante en die wisselende, tussen solidariteit en antitese. Hoe ernstiger en hoe suiwerder die spanning gedra word, hoe aktueler sal die boodskap voltrek word. Daarom duld dit geen ,meditation' in die sin van 'n spanninglose sintese, nog minder vermy dit die Scylla en Chaybdis van Woord en situasie. Dit ken alleen die dialektiese en dialogiese konfrontasie tussen Woord en situasie. Dit is alleen moontlik in navolging van Christus wat die spanning tussen beide pole gedra het en in Sy Kruis versoen het".4 Kotzé kom met dieselfde tema sonder variasie en verklaar met groot oortuiging: „Eers in die egte dialoog met die situasie word die appèl van die Woord verneem. In 'n leë situasie kan geen dialoog plaasvind nie en kan die Woord nie geïnterpreteer en geproklameer word nie. In die hede van die verkondiging moet 'n ontmoeting plaasvind tussen God en mens, tussen Woord en eksistensie. Vanuit die prediking moet 'n beweging uitgaan tot die tallose grondvrae van die bestaanswerreld. Sonder hierdie dialogiese beweging met die mens in die pluriformiteit van sy lewensverbande sal die prediking as 'n onsaaklike en verouderde aksie van die kerk deur die mens van ons dag afgeskrywe word". 5 En onmiddellik deel Kotzé dan ook nog verder 'n ligte klap uit aan die sogenaamde leerprediking as hy sê: „Hierdie dialogiese karakter is o.i. skromelik verwaarloos in die Woordstrukture van die Leerprediking..." Op „dialektiese" wyse sou ons wou vra: Wat 
van die „dialogiese" karakter van die Heidelbergse Kategismus?

Ons kan Müller en Kotzé se dringende betoë vir die prediking as dialoog saamvat in laasgenoemde se woorde: „Indien die verkondiging enige aktualiteit wil besit en behou vir die gekompliseerde hedendaagse situasie, sal hy hierdie dialogiese struktuur moet herwin".? Wat die saak egter so bedenklik maak, is dat hier nie eens die geringste poging aangewend word om vanuit die Skrif te redeneer nie, maar eenvoudig met 'n kompilasie vanuit die dialektiese teologie gewerk word. By die nagaan van die voetnote waarmee die lading gedek word, kry 'n mens 'n indruk hoe baie konklusies uit die dialektiese teologie eenvoudig kritiekloos oorgeneem word en opgedis word as ,gereformeerde beskouings". 'n Mens wil selfs vra of ons nog hier met teologie te doen het.

Die prediking as dialoog is die sogenaamde aktuele metode om die mens aan te gryp. Dit is dan nou die "nuwe" skema waarmee die meeste homiletiekboeke die prediking soos in 'n handelsadvertensie aanhoudend en oorverdowend aankondig: Prediking is dialoog!...'n voortdurende dialoog tussen twee entiteite: Woord en eksistensie of Woord en situasie. Dit is die spanning tussen twee pole wat deur Christus gedra word, soos wat Müller sê. In die Homiletiek is dit die nuwe interpretasie wat afreken en korte mette maak met die sogenaamde „onsaaklike en verouderde aksie van die kerk (wat) deur die mens van ons dag afgeskrywe word", soos wat Kotzé sê.

Teenoor hierdie dialektiese metode wat tans feitlik 'n algehele deurbraak in die gereformeerde Homiletiek gemaak het en oornag alreeds die kaart en transport in Stellenbosch ontvang het, vra ons verleë: Is daar nog plek vir 'n ander standpunt?

Dat ons verleë voel, is deels ons eie skuld, want wat het die predikante van die Gereformeerde Kerk in S.A. - ons wat vandag hier sit nou werklik in die laaste dekades met die hoogtefees van die dialektiek aangebied? Of wil ons maar slegs met Totius se rede oor „Het Preekmetode” van 1916 bly volstaan? Laat ons maar eerlik erken: Wat daar vanuit Suid-Afrika oor die problematiek van die predikkunde van gereformeerde kant gelewer is, het hoofsaaklik van die N.G. Kerk se kant gekom. Gaan tel slegs die aantal dissertasies en maak 'n opname van die literatuur! Sekerlik word die saak nie ten eerste deur die omvang bepaal nie, maar beslis ook nie deur niks te doen nie! Daarmee werk ons eenvoudig indirek mee dat die karikatuurbeeld van die sogenaamde „ou prediking” voortgedra word. Deur niks te doen nie laat ons toe dat daar onbillike, ongeregverdigde, maar nogtans rojale rekenings aan die "leerprediking wat stam uit die reformasie" gegee word. Deur in die diskussies oor die Homiletiek vir jare lank passief te wees, het ons toegelaat dat die indruk nog steeds bestaan dat verstarde skolastiek met ons dogmatiek in bottels met versterkwater op ons kansels, dan kwansuis ons antwoord is van wat gereformeerde prediking is!

Laat ons egter gaan kyk wat die apostel Paulus se beslissing was in die homiletiese krisis wat nie 'n nuwe probleem vir die kerk is nie, maar so oud soos ons Christelike jaartelling: 


\section{Die metode wat hy afgewys het}

In 1 Kor. $2: 4$ sê hy: „My rede (logos) en my prediking (kerugma) was nie in oorredende woorde van menslike wysheid nie..." En wat was nou hierdie "oorredende woorde van menslike wysheid"? Dit was niks anders nie as die dialektiek van die Griekse denkwêreld en by name die eis van welsprekendheid by die Sofiste, die manne van die „Wysheids-wysbegeerte". Dit was 'n bepaalde metode om tot die waarheid te kom. In die Griekse denkwêreld is dit deur die dialektief voorgestaan dat 'n mens deur redenasie, deur dialoog alleen die vraag na die waarheid kan beantwoord. Ons begryp dus ook Pilatus se vraag aan Jesus: „wat is waarheid"? (Joh. 18 : 38) want hy vra dit vanuit die Hellenistiese denkpatroon.

Die dialektiek as die begrip vir 'n sekere sisteem om tot kennis te kom, het natuurlik sy oorsprong in die Griekse werkwoord „dialegomai". In hierdie verband spreek Liddel en Scott in hulle standaard Griekse woordeboek van ,the dialectic method of the Socratics, where the conclusions were not drawn directly by the speaker, but elicited by discussion". Volgens hierdie metode het Plato sy dialoë geskryf en ontwikkel hy 'n dialektiese sisteem om van begrip tot begrip tot die hoogste ideë op te klim.9 Van Peursen toon aan dat die dialektiek in die retoriek 'n negatiewe betekenis kan kry as "slimme redeneermethode".10 Dit klop presies met wat William en Martha Kneale in hulle uitstekende werk: "The Development of Logic" oor die dialektiese metode in die Griekse wysbegeerte na vore bring: „If a consequence is unacceptable, the hypothesis from which it is derived must be rejected. It is clear that, in general, this procedure can lead only to negative results"."1

Sou dit oordrewe wees om te beweer dat as hierdie dialektiese metode op die prediking toegepas word, die gevolg met een woord, rampspoedig sal wees? Dit was juis die dialektiese skool onder die Griekse wysgere wat alle nadruk op die inadekwate karakter van die waarheidskennis gelê het deur teen elke positiewe stelling die negatiewe te stel.12 Dan bevind die prediking as dialoog homself voortdurend tussen ja en nee, tussen posisie en negas:e, tussen die stelling van 'n hipotese en onmiddellik daarna weer die opheffing daarvan, ens. Hier kry ons dan die sogenaamde ,dialektiese spanning" tussen die twee entiteite Woord en situasie of Woord en eksistensie. (Elke gebou wat opgerig word, word gesloop om weer 'n nuwe op te rig).

As die prediking dan alleen deur die metode van die dialoog sy wesensbetekenis kry, of soos wat Paulus dit in die eerste Korinthiërsbrief noem „met wysheid van woorde" $(1: 17)$, ,met voortreflike woorde" $(2: 1)$, „in oorredende woorde" $(2: 4)$, dan bly beide die prediker en die hoorders slegs die soekers na die waarheid, sonder die sekerheid dat hulle dit ooit sal vind! Die dialoog word dan die middelaar tot die moontlike waarheid en dit is nie meer 'n moontlike middel om die reeds vasstaande waarheid te demonstreer nie. Die metode van die preek word dan primêr en aktualiteit word gestoof in die spanning van die dialoog en nie meer ontbrand deur die Heilige Gees wat werk deur die inhoud van die Woord nie. 
En as Kotzé die eis van 'n ,dialogiese struktuur" as die enigste voorwaarde vir aktualiteit stel, dan het ons meteen alweer met 'n sisteem te doen, waarin die menslike woord 'n selfstandige entiteit teenoor God se Woord is. Die prediking tussen hierdie twee "pole" as dialoog word dan, om dit plat te stel, 'n ,ping-pong"-spel en vir die Homiletiek kan ons met dialoog as definisie van 'n preek ook nog 'n paar sub-definisies byvoeg soos die prediking is „Antwoord", of die prediking is ,'n vraag".'13 Müller skroom dan ook nie om te beweer dat dit die diepste sin van die prediking is om die mens na daardie Antwoord te lei nie. Nou word Antwoord met 'n hoofletter geskryf, want Jesus Christus is die Antwoord vir die vraende mens. ${ }^{14}$ Hierdie Antwoord word nou verder die "tweesnydende Antwoord" waarop die mens dan nou weer op sy beurt moet antwoord... En so moet die proses dan nou voortgaan. Dit kan ook nie anders nie, want die dialektiese metode het geen geduld met 'n afdoende, finale antwoord nie en om die vraagtekens so gou as moontlik te likwideer, moet die beste ,oorredende woorde" gekies word.

Daarvoor bedank die apostel Paulus hartlik, want hy weet: die oomblik wat hy sy prediking aktueel moet maak deur ' $n$ metode, dan word hy as prediker uitgelewer aan hierdie metode, maar wat erger is, die inhoud word uitgelewer; die kruis van Christus word verydel (1 Kor. 1 : 17). Of soos daar letterlik staan: die kruis word van sy krag beroof! En dan is die prediking glad nie meer aktueel nie. Calvyn teken hier aan: „Die prediking van die gekruisigde Christus is eenvoudig en naak... (m.a.w. dit is aktueel, V.E. d'A) ... daarom behoort dit deur geen versiering van woorde verduister te word nie". Deur 'n metode word die inhoud verbloem; mooi blomkranse word op Jesus se graf gelê.

Die apostel is doodbang dat daar maar een enkele iets afgedoen word aan die oorweldigende gesag van die Evangelie. Nooit mag 'n preekmetode die inhoud likwideer nie! Nooit mag 'n homiletiese metode van die inhoud sy dienswillige dienaar maak nie, maar dit is presies andersom: die metode is altyd, ja, altyd dienaar van die inhoud! En as die inhoud 'n struikelblok, 'n ,skandalon" is (1 Kor. $1: 23$ ) dan mag die preekmetode dit nie probeer verwyder nie. As die kruis 'n dwaasheid is, mag die „oorredende woorde" nie aanneemliker woorde as God kies nie!

Sal die debat tussen God en mens aan God se Woord meer krag gee? Sal die Koning se proklamasie meer gesag hê as Sy proklamasie elke keer 'n antwoord-proklamasie moet ontvang?

Nee, sê Paulus, ek het nie met julle in 'n debat getree nie, my „logos" en my „kerugma” was nie in oorredende woorde van menslike wysheid nie ... ek het nooit daaraan toegegee met die dialektiese metode nog te kom tot die waarheid nie, maar ek het van die waarheid as 'n vasstaande gegewene uitgegaan! Daarom was dit ,in die betoning van gees en krag".

Dit bring ons by die positiewe punt.

\section{Die metode wat hy wel gebruik het}

Teenoor die valse metode van die dialong of die sisteem van die 
dialektiek, stel Paulus nou die metode van sy prediking as die „,betoning”, of soos daar in die Grieks staan: die ,apodeiksis”. In die Logika as wetenskap (juis onder die Grieke), is dit die term vir die absolute bewys van die waarheid. Dit is waar ons woord ,apodikties" vandaan kom. Hiervan sê die groot Woordeboek van die Afrikaanse Taal: „Bewysend, oortuigend, onweerspreeklik, onweerlegbaar; waaraan die bewysbare noodsaaklikheid eie is". En H.A.T. verklaar apodikties as "met groot stelligheid, beslistheid".16

Die oorspronklike Griekse woord „apodeiksis" word in Liddel en Scott aangegee as die vasstaande bewys en verklaar dit verder o.a.: „In the logic of Aristoteles, demonstration, i.e. absolute proof by syllogistic deduction of a conclusion from known premises". ${ }^{17}$

Aristoteles was naamlik die man wat 'n onderskeid gemaak het tussen die twee redeneermetodes, nl. die dialektiese en die apodiktiese. ${ }^{18}$

Baie eenvoudig, kan ons dit soos volg stel: Die dialektiese metode moet deur redenasie, deur argumentasie, deur die debat, deur dialoog, nog kom tot die waarheid. In die apodiktiese metode is die waarheid reeds gegee. Die waarheid is reeds die uitgangspunt; dit word eenvoudig gekonstateer! Kneale stel dit soos volg: „The dialectical premiss ... is one adopted in debate for the sake of argument. From the logical point of view, however, the important distinction is that the demonstrative premiss (d.i. die ,apodeiksis', V.E. d'A) is true necessary, while the dialectical premiss need not be so". 19

En nou sien ons meteen wat 'n geweldige ding Paulus hier oor die prediking sê. Ons moet onthou dat hy in 'n Griekse stad gepreek het. Sy hoorders was mense wat deurknie was met die Griekse Wysbegeerte en hulle het presies geweet wat hy bedoel het met ,apodeiksis". Hulle moes baie duidelik weet: Sy logos en sy kerugma was nie dialekties nie, maar apodikties. Dit was nie 'n soektog na die waarheid deur middel van die dialoog nie, maar hy as prediker het reeds die waarheid besit. En toe het hy daarmee „kerugmaties” gewerk. Paulus het in die volle betekenis van die woord "kerugma" die waarheid soos 'n herout van sy Koning, aangekondig, uitgeroep, geproklameer!

Paulus moes eenvoudig die boodskap as 'n ewige vasstaande waarheid, as die absolute bewys, as die enigste ,apodeiksis" deurgee! En nou val daar nie meer te redeneer nie. Dit is geen oop vraag meer nie; geen dialogiese buiksprekery om die klank weer van die ander kant te laat kom nie !

Maar hiermee is die „betoning”, die absolute bewys, die finale ,apodeiksis" nog nie klaar nie. Dit was nie maar slegs ' $n$ betoning sonder meer nie.

En nou kom ons by die onafwendbare, knellende vraag van die prediking, nl. die vraag na die aktualiteit! Daaroor wil ons ten slotte ' $n$ paar positiewe opmerkings maak. Dit is die vraag na die eksistensiële werking van die Woord. (Let op, ons sê nie „eksistensialistiese" nie).

Hier staan: Die prediking was 'n betoning in gees en krag. 
En daarmee kry alle luiaards en slordige traak-my-nie-agtige dominees op die kansel die trekpas!

Met hierdie woorde word alle dorre, skolastieke „leerredes" wat met bombastiese cliches en 'n melodramatiese preekstyl voorgedra word tot bekering geroep.

Die Woord wat reeds aktueel is, die Evangelie met sy volle inhoud, nl. die ewige Logos, die lewende Christus - sy graf is leeg - kom staan nou in Sy Gees en krag voor die mens. Ons sal dit soveel beter begryp as ons, soos wat Grosheide dit duidelik aantoon, Gees hier met 'n hoofletter skryf! Die prediking is 'n betoning, 'n absolute bewys, ' $n$ apodeiksis van niemand minder as God die Heilige Gees nie.

Dit was op 'n datum na die Pinksterdag wat Paulus aan die Korinthiërs gepreek het en vandag staan ons nog steeds in die Pinksterbedeling... en tot by die Wederkoms sal dit steeds preektyd van die Heilige Gees bly.

En die „krag" waarin hierdie betoning is? In die vorige hoofstuk, vers 24, word Christus Self die „krag van God" genoem. Hy is die groot Dunamis van die prediking. Hy is nie maar 'n "Antwoord" op die kragtelose vraag van die mens nie, maar die Here van ons almal, ook van ons predikers... juis van ons predikers. Hy is die Koning wat Sy proklamasie na inhoud en metode bepaal... alleen deur Sy Woord.

Die toekoms van die Gereformeerde Kerk se prediking? Geen skemas... geen bloudruk-planne... geen Homiletiek-strukture volgens die smaak van die sondige mens nie.

Maar daar is één ding wat oorbly, broeders: Laat ons ons Bybels beter lees. En laat ons waarlik teoloë wees, predikers wat waarlik die kennis oor God besit. Dan sal ons die geeste nie alleen in die Homiletiekboeke nie, maar ook op die kansel kan beproef of hulle uit God is!

Laat ons altyd Skriftuurlik preek. Dit beteken: Laat ons apodikties preek en nie dialekties nie!

$$
\text { V. E. d'Assonville. }
$$

('n Voordrag gelewer voor die Jaarvergadering van die Gereformeerde Teologiese Vereniging, 8 Junie 1971, te Pretoria)

1 Kneale, William en Martha: The Development of Logic. Oxford 1964, p. 7.

2 Uitgegee deur J. Heinis Tsz., Zaandijk 1961.

3 Uitgegee deur Pro Rege-Pers Bpk., Potchefstrcom 1963.

4 Bl. 233.

5 Bl. 179-180.

6 Ibid.

7 Ibid.

8 Vgl. Müller: a.w., bl. 67; W. J. de Klerk: Wending, Potchefstroom, 1964, bl. 35. Die „leerprediking" stam tog nie eers uit die Reformasie nie. Wat van Augustinus se homiletiese advies: „Docere neccessitatis est, 


\section{In die Skriflig}

delectare suavitatis, flectere victoriae". Eerste „docere”, d.i. doserend, onderrigtend, lerend. (Augustinus wend hier 'n woord van Cicero aan vir gebruik in die Christelike prediking). Sien Augustinus se „De doctrina christiana, IV, xii, 27.

9 Christelijke Encyclopedie, Kampen, deel 2, 1957, bl. 402.

10 Ibid.

11 Kneale: a.w., bl. 7.

12 Chr. Encycl.: a.w., bl. 402.

13 Muller: a.w., bl. 257.

14 Ibid.

15 Woordeboek van die Afrikaanse Taal. Pretoria 1950, Deel I.

16 Handwoordeboek van die Afrikaanse Taal. Johannesburg 1965.

17 Liddel en Scott. Oxford 1929.

18 Kneale: a.w., bl. 1.

19 Ibid, bl. 2. 